\title{
Erratum to: Defense Categories and the (Category-Defying) De Minimis Defense
}

\author{
Melissa Beth Valentine ${ }^{1}$
}

Published online: 4 July 2017

(C) Springer Science+Business Media B.V. 2017

\section{Erratum to: Crim Law and Philos DOI 10.1007/s11572-016-9393-6}

In the original publication of the article, the corresponding author name was incorrectly published as "Melissa Beth Henzel". The correct author name is "Melissa Beth Valentine", which has been updated in the original article.

The online version of the original article can be found under doi:10.1007/s11572-016-9393-6.

$\triangle$ Melissa Beth Valentine

beth.henzel@gmail.com

1 Philosophy Department, Rutgers University, New Brunswick, NJ, USA 